\title{
Comparison between Augmentation Mastopexy in One Session and Two Separate Sessions
}

\author{
MOHAMMED Kh. ATALLAH, M.D.*; AHMED G. EL-DIN OSMAN, M.D.*; \\ SARAH A. ABDALMAKSOUD FARRAG, M.D.** and AHMED RAMADAN EL SABBAGH, M.Sc.* \\ The Department of General Surgery* and Department of Plastic, Burn and Maxillofacial Surgery**, Faculty of Medicine, \\ Ain Shams University
}

\begin{abstract}
Background: Breast ptosis is a growing disfiguring and psychosocial problem which has gained greater attention recently. Moderate and sever degrees of breast ptosis is corrected surgically through augmentation-mastopexy operation using breast implant to enhance the breast tissue and resection of excess skin. It is whiter done in one session or in two separate sessions; mastopexy followed by breast augmentation in second stage. The choice between the two technique has been a controversy since each has special challenges.
\end{abstract}

Aim of Study: To draw a comparison between the two techniques in the treatment of $2^{\text {nd }}$ and $3^{\text {rd }}$ degree of breast ptosis, augmentation-mastopexy using silicone implants in one session versus in two separate sessions (mastopexy followed by breast augmentation in $2^{\text {nd }}$ stage), regarding patient satisfaction, clinical outcome and complications in a period of 6 months post-operatively.

Patients and Methods: This is a retrospective cohort study comparing the two techniques of augmentation-mastopexy regarding patient satisfaction and quality of life along with clinical outcome and complications. Two groups of 15 patients each; G1 having one stage and G2 having two stages augmentation-mastopexy. All cases were operated on in time period from 2015 to mid-2019 with mean follow-up time of 2.5 years in both groups and minimum of 6 months for each case.

Results: G1 and G2 reached satisfaction about the breast after operation by $75 \%$ and $72 \%$ respectively with increase in satisfaction than before surgery by $55.47 \%$ and $56.27 \%$, G1 was satisfied with outcome of operation by $82.47 \%$ vs. $78.47 \%$ in G2, psychosocial wellbeing increased by $66.07 \%$ in G1 vs. $54.54 \%$ in G2, physical wellbeing regarding breast area showed $0.07 \%$ decrease in G1 vs. decrease by $10.87 \%$ in $\mathrm{G} 2$ in form of pain and discomfort in chest and breast during exercise, sexual wellbeing and confidence in breast area and in front of partner were increased by $60.74 \%$ in G1 vs. $56.14 \%$ in G2, regarding clinical observation all cases of G1 was suffering from grade 2 ptosis, 2 cases of $\mathrm{G} 2$ were of grade 3 ptosis and the rest were of grade 2, all degrees of

Correspondence to: Dr. Ahmed Ramadan El Sabbagh, E-Mail: doc.ahmad@hotmail.com ptosis were corrected post operatively, no recurrence of ptosis in period extended to 6 months after operation, $13.3 \%$ of cases in G1 had wound infection vs. $6.67 \%$ in $\mathrm{G} 2,20 \%$ of cases in G1 had wound disruption vs. no disruption noticed in G2, scar widening reached up to $46.67 \%$ of cases in G2 (after $2^{\text {nd }}$ stage) vs. $33.3 \%$ in G1, also capsular contracture happened in one case only of G2 by incidence of $6.66 \%$ vs. no incidence in cases of G1, no extrusion of implant in both groups.

Conclusion: The study reveals that both techniques are effective in treatment of breast ptosis with no significant difference in patient satisfaction and clinical complications. And there is no added risk for combining the procedure; moreover, one stage technique excludes a $2^{\text {nd }}$ operation. A more obvious comparative values between the two techniques and late post-operative complications and long-term results need to be determined by further studies on a larger scale of patients and longer duration of follow-up.

Key Words: Human placental lactogen - Infra-mammary fold - Nipple areola complex - Supra-sternal notch.

\section{Introduction}

IN the normal anatomy of breast, gland extends from second to sixth rib, the nipple areola complex 'NAC' located above the infra-mammary fold 'IMF' and centralized over breast mound in the fourth intercostal space in a non-ptotic breast, average supra-sternal notch 'SSN' to 'NAC' distance is 19 to $21 \mathrm{~cm}$, and average NAC to IMF is 6 to $7 \mathrm{~cm} \mathrm{[1].}$

Breast ptosis refers to the inferior and lateral descent of the NAC in relation to the IMF and breast tissue, a classification system commonly used describes first degree or mild ptosis as a nipple position within $1 \mathrm{~cm}$ of the IMF. In second degree, or moderate ptosis, the nipple is located 1 to $3 \mathrm{~cm}$ below the IMF and on the anterior surface of the breast mound. In third-degree, sever ptosis; the NAC is below the IMF and on the lowest portion of the inferior breast pole [2]. 
Breast ptosis is considered as one of the most common conditions treated by plastic surgeons. Regnault considered the postpartum or menopausal glandular hormonal regression, massive or postbariatric surgery weight loss as the most important causes of breast ptosis [3].

Breast ptosis etiology has a multi-factorial nature and can be affected by many factors such as race, culture, body composition, age, as well as hormonal changes. Regression of the glandular tissue due to hormonal changes after menopause or pregnancy, weight loss, skin pathologies, and previous surgery have been mentioned as potential causes of breast ptosis [4].

Massive weight loss makes changes to the breasts in the form of skin laxity, flattening and flaccidity, reduced projection. Both the nipples and infra-mammary fold (IMF) descend, most cases benefit from both augmentation and mastopexy [5].

Also the claim that breast ptosis can be corrected through exercise has no scientific evidence yet, and scientifically, there is no mechanism through which increasing the pectoralis muscle strength would tighten the suspensory system of the breast [3].

Several surgical procedures have been described for breast re-shaping. Breast augmentation and mastopexy represent two surgical procedures with different objectives, the first one is performed to increase breast volume and eventually restore symmetry, while the main goal of mastopexy is to raise the nipple-areola complex (NAC), aiming the result of a natural, firm and youthful breast. Both augmentation and mastopexy are necessary when both breast ptosis and hypoplasia are present. Simultaneous augmentation/mastopexy debates have often questioned which surgical technique to adopt and when to perform it [6].

Excision of the excess skin and enhancing the breast volume is the key to correct breast ptosis, mastopexy and breast augmentation by implant whether in the same setting or in two separate sessions, is most satisfactory in most of cases [7].

Some authors have considered staging the two operations, allowing for more desirable results with lower incidence of wound complications and tissue distortion. Although a 2-stage operation may give a more reliable outcome, a second operation is a must [8].

On the other hand, single stage mastopexy with augmentation remains a popular procedure among surgeons performing breast surgery. These combined two operations increase breast size and correct ptosis in a single surgical procedure [9].

Some authors reporting that "simultaneous timing of these operations does not add any additional risks". Other studies have focused more on operative strategies, such as surgical techniques and patient selection, in order to achieve acceptable results [10].

\section{Aim of the work:}

The aim of this study is to draw a comparison between the two techniques in the treatment of $2^{\text {nd }}$ and degree of breast ptosis, augmentationmastopexy using silicone implants in one session versus in two separate sessions (mastopexy followed by breast augmentation in ${ }^{\text {nd }}$ stage), regarding patient satisfaction, clinical outcome and complications in a period of 6 months post-operatively.

\section{Patients and Methods}

Study design:

This is a retrospective Cohort study on preand post-operative data of cases which was operated on at Ain Shams University Hospitals and other authorized hospitals under supervision of Ain Shams University thesis supervisors, studying the comparison between augmentation-mastopexy operation in one session and in two separate sessions regarding patient satisfaction and quality of life along with surgical outcome and complications.

In this study, a review of a selected 30 cases of breast ptosis of ${ }^{2 n d}$ and 3 rd degree according to Regnauld's classification of different causes, having a recent breast-lift surgery and a silicone implant for breast ptosis correction, aging from 20 to 50 years at the time of operation, cases were operated on between 2015 and 2019.

All patients were consented to participate in the study. Ethical approval from Ain Shams University Hospitals Ethics Committee was obtained. confidentiality was assured for the personal data and medical information of all patients.

\section{Patients:}

Inclusion criteria: Female patients aged between 20 and 50 years with post-weight loss, postlactational, post-bariatric or idiopathic grade 2 or 3 breast ptosis with inadequate breast volume that underwent an augmentation-mastopexy operation for breast lifting. A psychologically stable patient with realistic expectations. A well informed and motivated patient. Supportive family/social environment. Committed to long term follow-up. No 
alcohol or substance abuse and no diabetes or chronic illness.

Exclusion criteria: Patient age $<20$ or $>50$. Any patient with previous surgery in breast area, or breast tumors. Alcohol or substance abuse or diabetic patients. Psychological illness.

\section{Study procedures:}

The 30 cases were divided into two groups, 15 patients each: Group 1 (G1) have an augmentationmastopexy operation in one session using a silicone gel implant to enhance the breast tissue along with a skin resection using a peri-areolar or vertical incision mastopexy. Group 2 (G2) have a mastopexy operation using a vertical incision and skin resection in the first session, followed by breast augmentation using a silicone gel implant in a second separate session.

\section{Methods:}

\section{Pre-operative assessment:}

Pre-operative preparation: Full clinical history including patient demographics and full medical history. Routine pre-operative blood tests (complete blood picture, coagulation profile liver and kidney functions tests and Fasting Blood Sugar).

Pre-operative assessment: Clinical examination including anthropometric measurements (SSN to NAC, NAC to IMF, degree of ptosis). Assessment of quality of skin and skin pinch test Pre-operative BREAST-Q satisfaction questionnaire. Marking of the breast parameters and the planned procedure with photography.

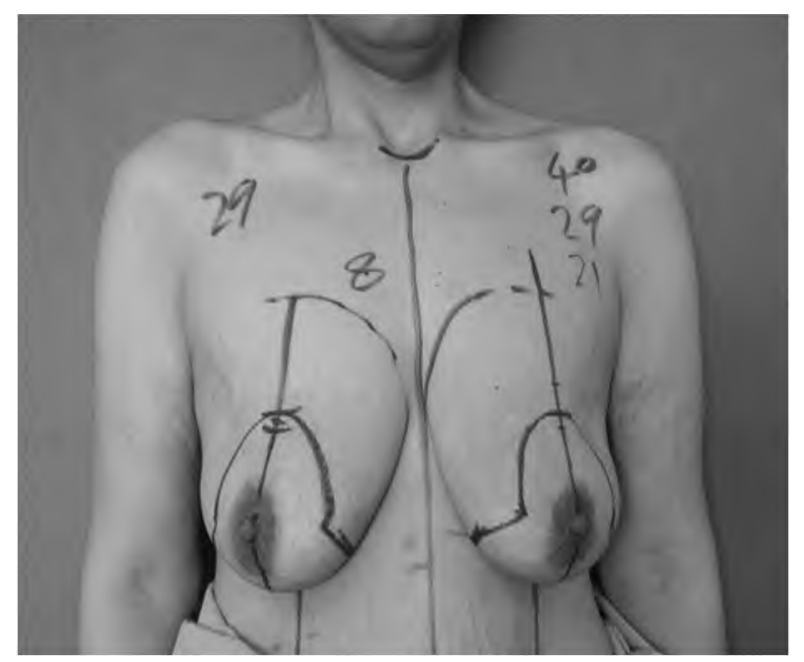

Fig. (1): Pre-operative marking of a case of mastopexy showing the following: age of patient (40yrs), midline, breast meridian (crossing the nipple), SSN to NAC $(29 \mathrm{~cm})$ bilateral, SSN to new NAC $(21 \mathrm{~cm})$ and breast meredian to midline $(8 \mathrm{~cm})$.

\section{Operative techniques:}

Regarding augmentation-mastopexy in one session (group 1):

Marking was done with patient standing upright, a midline was drown from the supra-sternal notch (SSN) to the umbilicus, the breast meridian was marked joining a point $6-8 \mathrm{~cm}$ lateral to the suprasternal notch to the mid-point of the breast. This line is usually marked $10-15 \mathrm{~cm}$ from the midline. Marking of IMF to chest midline. Future ideal nipple position was marked on the breast meridian 19 to $21 \mathrm{~cm}$ far from SSN; 10 to $15 \mathrm{~cm}$ from midline as mentioned before. The peri-areolar margin was drawn about $2 \mathrm{~cm}$ above the point of the new nipple position so as the diameter of the new areola will be $4-4.5 \mathrm{~cm}$ marked by a nipple marker, while the distance between the NAC to IMF will be about 6 to $8 \mathrm{~cm}$ long to meet at a point about $1 \mathrm{~cm}$ above the old IMF. The superior limit of the dissection is marked at the level of the second rib. Lateral markings are decided after pushing the breast to medial and lateral sides; the lower margin is drawn $1 \mathrm{~cm}$ above the IMF and connects lateral and medial lines. All the procedures were performed under general anesthesia. Patient was put in supine position. A preoperative injection of $600 \mathrm{mg}$ Averozolid vial intravenous was given as routine prophylaxis, or $500 \mathrm{mg}$ of Tavanic vial was given in patients allergic to Averozolid. A solution composed of $\mathrm{NaCl} 0.9 \%$ and adrenaline in concentration of 1:500,000 was injected sub-dermally to the planned area of de-epithelization and along the incision planes to maintain hemostasis. A new areola measuring 4 to $4.5 \mathrm{~cm}$ in diameter was marked using a nipple-marker. An incision was made according to the preoperative marking. In vertical augmentationmastopexy areola is left in its position; and the upper and lower areas of skin surrounding the new areola was de-epithelized extending to the IMF resembling a key-hole area of de-epithelization. Excision of lower breast tissue in v-shaped manner and the resulting superior pedicle is transposed upward and part maybe excised according to the desired volume and the skin envelop capacity. A PDS absorbable round zero loop pillar suture is taken joining the medial and lateral breast tissue at the level of new IMF.

Plane of dissection for implant insertion: A sub-glandular round textured silicone implant of a volume between $275 \mathrm{ml}$ and $315 \mathrm{ml}$ from the same manufacturer was placed directly above the pectoral fascia in a plane of dissection extending medially and laterally bounded by the breast tissue and guided by the marking preoperatively and extending from the IMF inferiorly to the extent of breast 
tissue superiorly and not exceeding the second rib. After placement of the implant, the pillar sutures are taken at the new IMF. NAC transposition with inset into new position. Final scar is peri-areolar plus vertical scar from NAC to IMF. In a periareolar augmentation mastopexy only round area of skin around the NAC is de-epithelized without a vertical extension and the silicone implant is placed through an incision at the IMF and a plane of dissection as described in the vertical technique.

Regarding the augmentation-mastopexy in two separate sessions (group 2):

A vertical mastopexy is done at first and followed by breast augmentation using a sub-glandular silicone implant through an infra-mammary incision after 6 months.

\section{Postoperative assessment:}

Post-operative care: Post-operative hospital stay and medications. Follow-up for drains. Observing for complications occurrence and management in case encountered.

Post-operative assessment: Follow-up by measurements and photography at ${ }^{3 \mathrm{rd}}$ and ${ }^{\text {th }}$ month after operation. Post-operative BREAST-Q satisfaction questionnaire.

Perioperative care: Peri-operative management was standardized. All patients were submitted to the same level of evaluation for the degree of ptosis, preoperative preparation and medications. In general, patients were discharged on the same day or one day after. Postoperative follow-ups were scheduled for the first postoperative week for wound evaluation and drains removal, and at postoperative months 1, 3 and 6 months thereafter. Photography and measurement of SSN to NAC and NAC to IML were evaluated at 1, 3 and 6 months of post-operative patient visits.

Evaluation of the procedures: In this study we aimed to combine the two ways of evaluation, the patient viewpoint and surgical assessment along with studying the final results through observing the complication and degree of correction. Each of the two groups' individuals was conducted to three levels of evaluation to collect data essential for the study as the following.

\section{Subjective evaluation:}

Satisfaction questions to the patients using standard BREAST-Q questionnaire, it has been developed using the psychometric methods and validated with strict adherence to the MOT "the scientific advisory committee of the Medical Out- comes Trust" guidelines and the FDA "the US Food and Drug Administration" (U.S. Food and Drug Administration, Accessed May 20, 2008).

The questionnaire measures the effect of breast augmentation on the quality of patient's life, as well as satisfaction with their surgery and the process of care.

The BREAST-Q Augmentation module, which we chose to apply on the cases of our study groups, as it is a fixed tool to all the study population, has both pre and post-operative domains. The postoperative questionnaire questions contain all of the items in the pre-operative questionnaire plus additional questions to measure satisfaction with process of care and treatment issues (full copy of BREAST-Q questionnaire is included at the end of this study).

BReast-q Augmentation module:

Table (1): Domains of BREAST-Q questionnaire.

Quality of Physical Psychosocial Sexual life Domains Well-being Well-being Well-being

BREAST-Q Satisfaction Satisfaction Satisfaction Satisfaction questionnaire Domains with Breasts with Outcome with care

Quality of life domains: Psychosocial Wellbeing, sexual Well-being and physical Well-being of Chest and Upper Body.

Satisfaction domains: Satisfaction with Breasts, Satisfaction with Outcome and Satisfaction with Care.

BREAST-Q questionnaire is designed to measure pre and post-operative satisfaction and quality of life regarding breast area including questions about psychosocial, sexual and physical wellbeing before and after the operation, questionnaire was translated to Arabic after contact with MAPI trust organization, they provided us with the guidelines for linguistic validation and translation as the Arabic language wasn't supported.

The BREAST-Q is a self-administered questionnaire. The entire BREAST-Q module can be completed in about 10 to 15 minutes. Each scale takes 1 to 4 minutes to complete. No specific training is required to complete any module of the BREAST-Q. Patients were given instructions in an introductory paragraph at the beginning of the questionnaire, it was also conducted to patients through direct visits to examination room or sent through 'what's app' application, and answers were processed by a BREAST-Q score system. 
Scale Scoring: Each of the scales for the BREAST-Q Augmentation module is scored separately and reported on a 0 to 100 scale, as patients are answering questions on a 1 to 5 value Likert scale, scores must be transformed to obtain the 0 to 100 value, this is achieved by summing the responses of each questionnaire scale and using a conversion table 'Q-score program' to obtain the 0 to 100 score [11].

\section{Objective evaluation:}

Measurements: Revising data of measurements taken pre and post operatively, an assessment for degree of ptosis for all cases according to Regnauld's classification was done as following; Grade I Minor Nipple at the infra-mammary fold. Grade II Moderate Nipple below the infra-mammary fold but above lower breast contour. Grade III Severe Nipple at lower breast contour.

Cases included in the research were of grade 2 and 3. The distance between supra-sternal notch (SSN) and nipple-areola complex (NAC) were measured in all patients, however, it's not a fixed tool for evaluation of the degree of ptosis as it ranges according to each individual, but it can give a good indication for degree of correction to every case separately. Distance between NAC and IMF. Photography of the patients pre and post-operatively were taken and reviewed to assess degree of ptosis and to observe complications.

Assessment of Complications A post-operative assessment for all cases in a period of six months dating since surgery was performed; complications sought for were; wound infection, disruption, extrusion of the implant, scar widening, recurrent ptosis and capsular contracture.

\section{Statistical analysis:}

The collected data was revised, coded, tabulated and introduced to a PC using statistical package for social science (SPSS 15.0.1 for Windows; SPSS Inc., Chicago, IL, 2001). Data was presented as mean and standard deviation for quantitative parametric data. Frequency and percentage were used for presenting qualitative data; analysis was done according to the type of data obtained. Student $t$ test and Mann Whitney test were used to analyze quantitative data while qualitative data will be analyzed by Chi square test and fisher exact test. Probability ( $p$-value): $p$-value: Level of significance. $p$-value $\leq 0.05$ will be considered statistically Significant (S). $p$-value $\leq 0.001$ was considered as highly significant. $p$-value $>0.05$ was considered insignificant.

\section{Results}

Table (2): Demographic data (one stage).

\begin{tabular}{|c|c|c|c|c|c|}
\hline & $\mathrm{N}$ & Min. & Max. & Mean & SD \\
\hline Age (years) & 15 & 19.00 & 45.00 & 32.80 & 8.55 \\
\hline \multirow{3}{*}{$\begin{array}{l}\text { Grade of ptosis: } \\
\text { I } \\
\text { II }\end{array}$} & \multicolumn{3}{|r|}{$\mathrm{N}$} & \multicolumn{2}{|c|}{$\%$} \\
\hline & \multirow{2}{*}{\multicolumn{3}{|c|}{15}} & \multicolumn{2}{|c|}{0.0} \\
\hline & & & & \multicolumn{2}{|c|}{100.0} \\
\hline Total & \multicolumn{3}{|r|}{15} & \multicolumn{2}{|c|}{100.0} \\
\hline
\end{tabular}

Table (3): Incision (one stage).

\begin{tabular}{llc}
\hline Incision type & $\mathrm{N}$ & $\%$ \\
\hline Periareolar+inframammary (PAM+IMI) & 8 & 53.3 \\
Circum-vertical (V) & 7 & 46.7 \\
\hline Total & 15 & 100.0 \\
\hline
\end{tabular}

Table (4): Pre and Post-operative measurements (one stage).

\begin{tabular}{llllll}
\hline \multicolumn{1}{c}{ Min. } & Max. & Mean & SD & $t^{*}$ & $p$-value \\
\hline SSN $\rightarrow$ NAC pre-op. 22.00 & 31.00 & 25.33 & 2.26 & 9.44 & $<0.001$ \\
SSN $\rightarrow$ NAC post-op. 19.00 & 24.00 & 20.93 & 1.28 & & HS \\
NAC $\rightarrow$ IMF pre-op. 4.00 & 7.00 & 5.23 & 0.88 & 15.10 & 0.01 \\
NAC $\rightarrow$ IMF post-op. 6.00 & 9.00 & 7.30 & 0.86 & & HS \\
\hline
\end{tabular}

*Paired samples $t$-test.

Table (5): Complications (one stage).

\begin{tabular}{lll}
\hline & $\mathrm{N}$ & $\%$ \\
\hline Extrusion: & & \\
Yes & 0 & 0.0 \\
No & 15 & 100.0 \\
Infection: & & \\
Yes & 2 & 13.3 \\
No & 13 & 86.7 \\
Disruption: & & \\
Yes & 3 & 20.0 \\
No & 12 & 80.0 \\
Scar widening: & & \\
Yes & 5 & 33.3 \\
No & 10 & 66.7 \\
Capsular contracture: & & \\
Yes & 0 & 0.0 \\
No & 15 & 100.0 \\
Recurrent ptosis: & & \\
Yes & 0 & 0.0 \\
No & 15 & 100.0 \\
\hline
\end{tabular}

Table (6): BREAST-Q questionnaire Pre-operative (one stage).

\begin{tabular}{llllc}
\hline & Min. & Max. & Mean & SD \\
\hline Satisfaction with Breasts pre-op. & 0.00 & 50.00 & 19.47 & 20.95 \\
Psychosocial Well-being pre-op. & 0.00 & 62.00 & 20.33 & 20.18 \\
Physical Well-being pre-op. & 66.00 & 100.00 & 93.60 & 12.22 \\
Sexual Well-being pre-op. & 0.00 & 65.00 & 19.33 & 16.47 \\
\hline
\end{tabular}


Table (7): BREAST-Q questionnaire post-operative (one stage).

\begin{tabular}{lcccc}
\hline & MM. & Max. & Mean & SD \\
\hline Satisfaction with Breasts post-op. & 57.00 & 100.00 & 74.93 & 16.33 \\
satisfaction with outcome-op. & 44.00 & 100.00 & 82.47 & 19.83 \\
Psychosocial Well-being post-op. & 66.00 & 100.00 & 86.40 & 14.41 \\
Sexual Well-being post-op. & 65.00 & 100.00 & 80.07 & 13.40 \\
Physical Well-being post-op. & 67.00 & 100.00 & 93.53 & 11.03 \\
Satisfaction with Information & 55.00 & 100.00 & 72.60 & 20.83 \\
Satisfaction with Surgeon & 54.00 & 100.00 & 84.27 & 20.09 \\
Satisfaction with Medical staff & 59.00 & 100.00 & 73.67 & 19.46 \\
Satisfaction with Office Staff & 53.00 & 100.00 & 78.40 & 21.41 \\
\hline
\end{tabular}

Difference between BREAST-Q questionnaire score pre and post-operatively:

Table (8): Difference between BREAST-Q questionnaire score pre and post-operatively (one stage).

\begin{tabular}{lllllcc}
\hline & MM. & Max. & Mean & SD & $\begin{array}{c}\text { Value of test of } \\
\text { significance }\end{array}$ & $\begin{array}{c}P^{-} \\
\text {value }\end{array}$ \\
\hline Satisfaction with Breasts pre-op. & 0.00 & 50.00 & 19.47 & 20.95 & $3.411^{*}$ & $0.001 \mathrm{HS}$ \\
Satisfaction with Breasts post-op . & 57.00 & 100.00 & 74.93 & 16.33 & & \\
PsychoSocial Well-being pre-op. & 0.00 & 62.00 & 20.33 & 20.18 & $3.409^{*}$ & $0.001 \mathrm{HS}$ \\
PsychoSocial Well-being post-op & 66.00 & 100.00 & 86.40 & 14.41 & & \\
Physical Well-being pre-op & 66.00 & 100.00 & 93.60 & 12.22 & $0.02^{* *}$ & $0.98 \mathrm{NS}$ \\
Physical Well-being post-op. & 67.00 & 100.00 & 93.53 & 11.03 & & \\
Sexual Well-being pre-op. & 0.00 & 65.00 & 19.33 & 16.47 & $12.87^{* *}$ & $<0.001 \mathrm{HS}$ \\
Sexual Well-being post-op. & 65.00 & 100.00 & 80.07 & 13.40 & & \\
\hline
\end{tabular}

HS: High significance.

NS: Non-significant.

* Wilcoxon Signed Ranks Test.

**Paired Samples t-test.

(A)
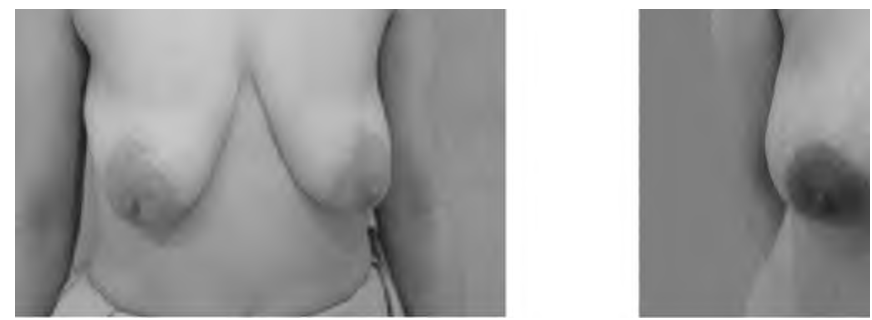

(B)
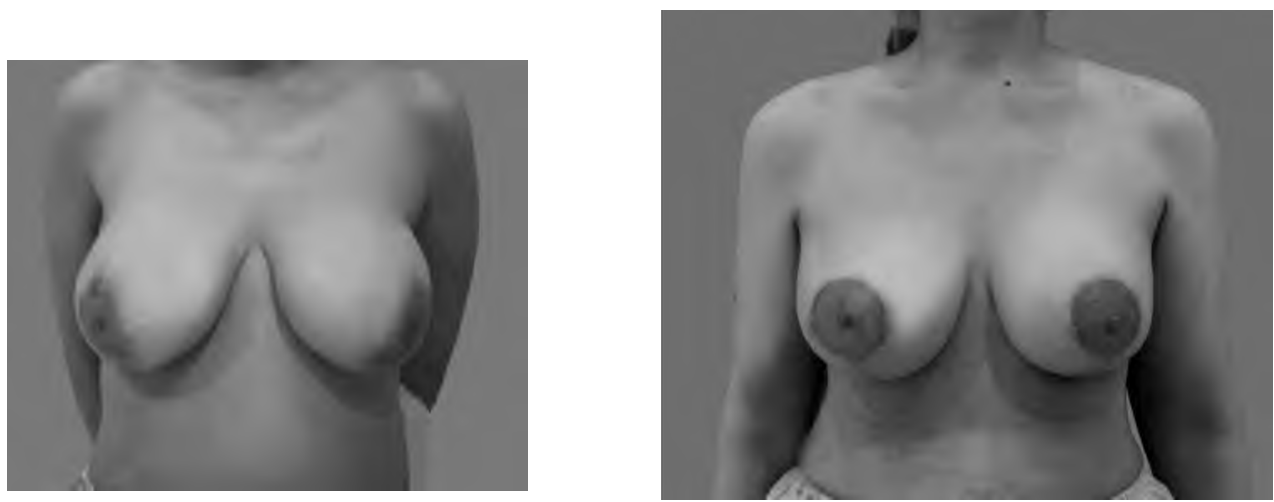

Fig. (2): Pictures of 2 cases from G1 (augmentation-mastopexy in one session) showing: (A) Pre-operative pic. of two cases having breast ptosis. (B) Post-operative pic. (6 months) after one-stage augmentationmastopexy. (Peri-areolar technique was done for the patient on the left and vertical technique for the patient on the right). 
Table (9): Demographic data (two stages).

Table (11): Complications (two stages).

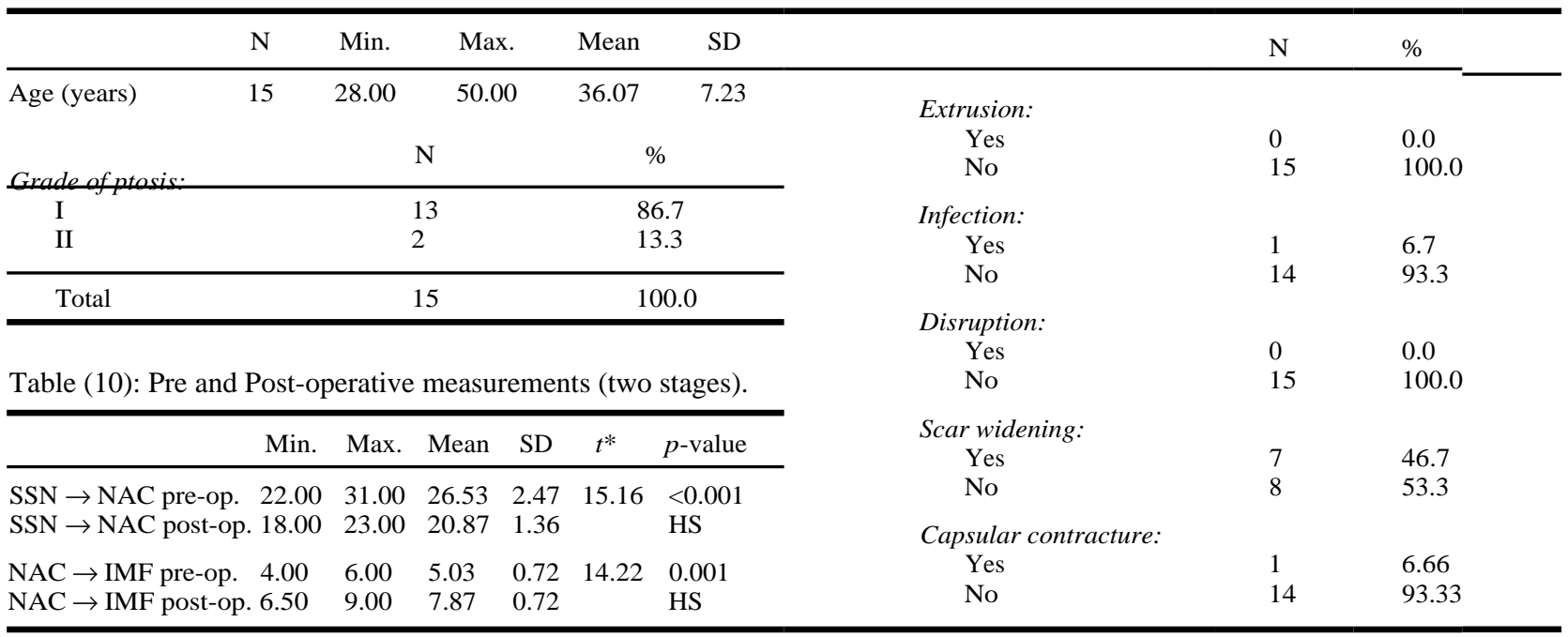

*Paired samples $t$-test.

Table (12): BREAST-Q questionnaire pre-operative (two stages).

\begin{tabular}{lllll}
\hline & Min. & Max. & Mean & SD \\
\hline Satisfaction with Breasts pre-op. & 0.00 & 46.00 & 15.60 & 17.34 \\
Psychosocial Well-being pre-op. & 0.00 & 58.00 & 25.73 & 24.42 \\
Physical Well-being pre-op. & 100.00 & 100.00 & 100.00 & 0.00 \\
Sexual Well-being pre-op. & 0.00 & 53.00 & 24.27 & 19.73 \\
\hline
\end{tabular}

Table (13): BREAST-Q questionnaire post-operative (two stages).

\begin{tabular}{lcccc}
\hline & Min. & Max. & Mean & SD \\
\hline Satisfaction with Breasts post-operative & 22.00 & 100.00 & 71.87 & 18.72 \\
satisfaction with outcome & 22.00 & 100.00 & 78.47 & 24.89 \\
Psychosocial Well-being post-operative & 34.00 & 100.00 & 80.27 & 25.36 \\
Sexual Well-being post-operative & 33.00 & 100.00 & 80.40 & 19.24 \\
Physical Well-being post-operative & 64.00 & 100.00 & 89.13 & 14.45 \\
Satisfaction with Information & 0.00 & 100.00 & 60.27 & 20.54 \\
Satisfaction with Surgeon & 0.00 & 100.00 & 80.73 & 27.77 \\
Satisfaction with Medical staff & 59.00 & 100.00 & 83.00 & 14.49 \\
Satisfaction with Office Staff & 58.00 & 100.00 & 77.13 & 16.23 \\
\hline
\end{tabular}

Table (14): Difference between BREAST-Q questionnaire score pre and post-operatively (two stages).

\begin{tabular}{|c|c|c|c|c|c|c|}
\hline & Min. & Max. & Mean & SD & $\begin{array}{l}\text { Value of test of } \\
\text { significance }\end{array}$ & $\begin{array}{c}p- \\
\text { value }\end{array}$ \\
\hline Satisfaction with Breasts pre-op. & 0.00 & 46.00 & 15.60 & 17.34 & $3.41 *$ & $0.001 \mathrm{HS}$ \\
\hline Satisfaction with Breasts post-op. & 22.00 & 100.00 & 71.87 & 18.72 & & \\
\hline Psychosocial Well-being pre-op. & 0.00 & 58.00 & 25.73 & 24.42 & $3.24 *$ & $0.001 \mathrm{HS}$ \\
\hline Psychosocial Well-being post-op. & 34.00 & 100.00 & 80.27 & 25.36 & & \\
\hline Physical Well-being pre-op & 100.00 & 100.00 & 100.00 & 0.00 & $2.91 * *$ & $0.01 \mathrm{HS}$ \\
\hline Physical Well-being post-op. & 64.00 & 100.00 & 89.13 & 14.45 & & \\
\hline Sexual Well-being pre-op. & 0.00 & 53.00 & 24.27 & 19.73 & $8.60 * *$ & $<0.001 \mathrm{HS}$ \\
\hline Sexual Well-being post-op. & 33.00 & 100.00 & 80.40 & 19.24 & & \\
\hline
\end{tabular}

* Wilcoxon Signed Ranks Test.

**Paired Samples $t$-test. 
(A)

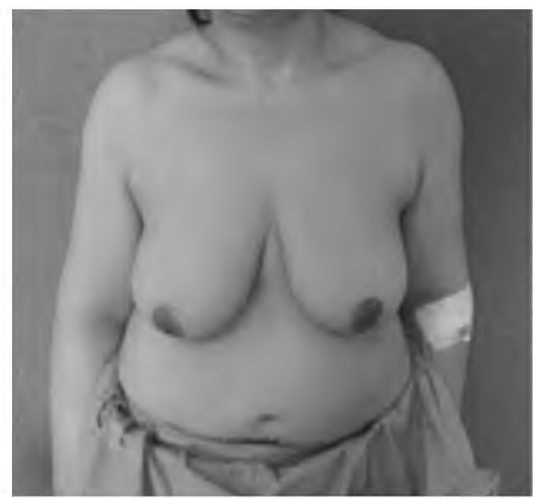

(B)

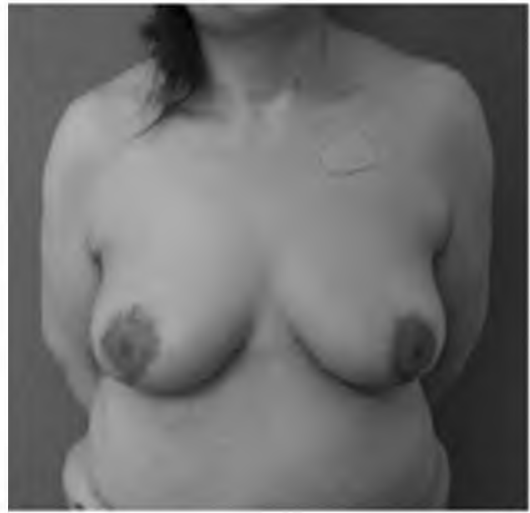

(C)

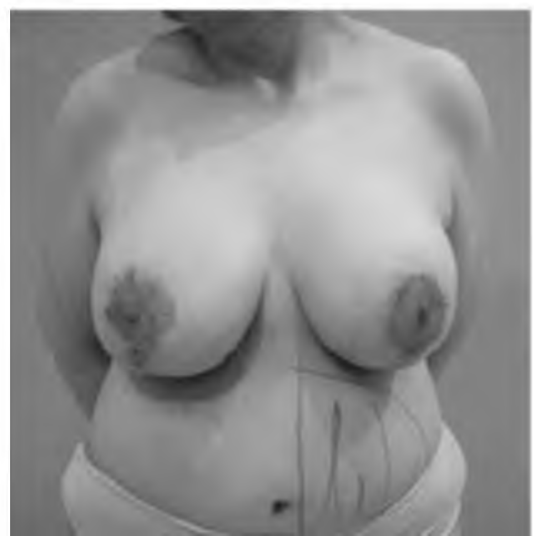

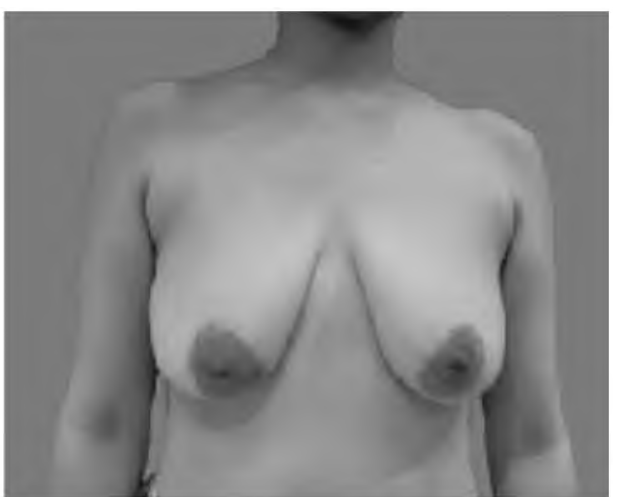
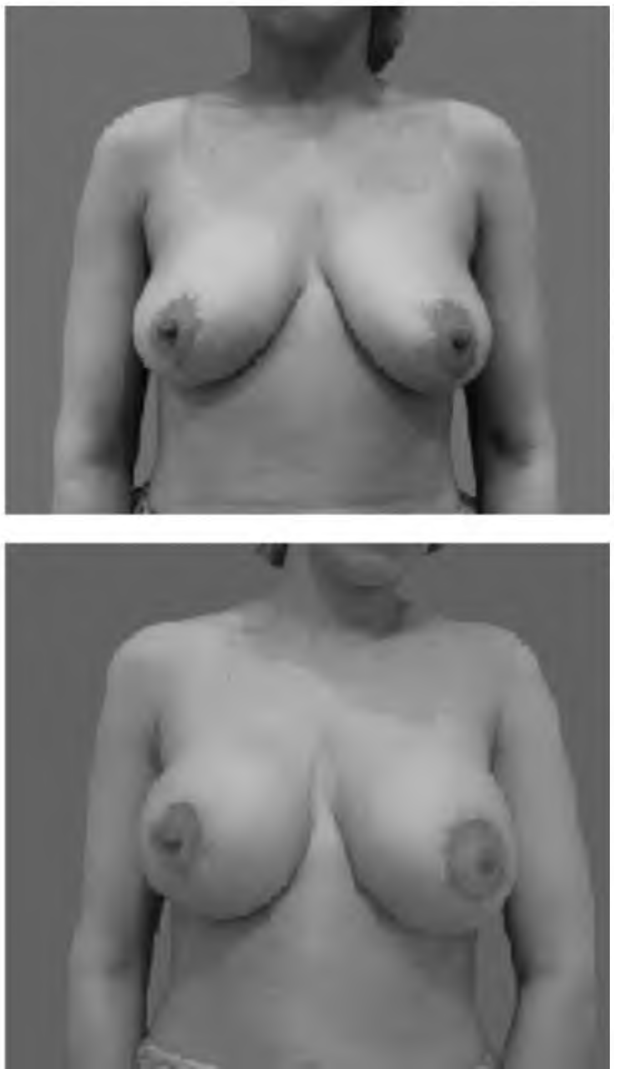

Fig. (3): Pictures of 2 cases of G2 (augmentation-mastopexy in two sessions) showing: (A) Pre-operative pic. of two patients having breast ptosis, planned vertical mastopexy ( $1^{\text {st }}$ stage). (B) Post-operative pic. (6 months post-mastopexy). (C) Post-operative pic. ( $2^{\text {nd }}$ stage) $(6$ months post two-stage augmentationmastopexy).

Table (15): Comparison of demographic data between G1 and G2.

\begin{tabular}{llllllll}
\hline & \multicolumn{2}{c}{ One stage group } & \multicolumn{2}{c}{ Two stages group } & \multirow{2}{*}{$t^{*}$} & & $p$-value \\
\cline { 2 - 4 } & Mean & SD & Mean & SD & & \\
\hline Age & 32.80 & 8.55 & 36.07 & 7.23 & & 1.13 & $0.27 \mathrm{NS}$ \\
& $\mathrm{N}$ & $\%$ & $\mathrm{~N}$ & $\%$ & $\mathrm{X}^{2} * *$ & $p$-value \\
Grade of ptosis: & & & & & & \\
$\quad$ I & & 0.0 & & 0.0 & 2.60 & $0.26 \mathrm{NS}$ \\
$\quad$ II & 15 & 100 & 13 & 86.7 & & \\
III & & 0.0 & 2 & 13.3 & & \\
\hline
\end{tabular}

*Student $t$-test. $\quad * *$ Fisher Exact test. 
Table (16): Comparison of pre-operative measurement between $\mathrm{G} 1$ and $\mathrm{G} 2$.

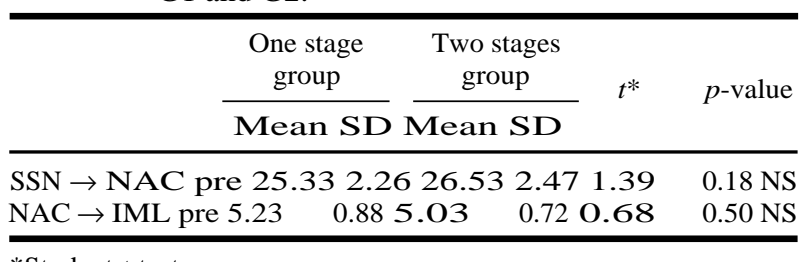

Table (17): Comparison of post-operative measurements between $\mathrm{G} 1$ and G2.

\begin{tabular}{|c|c|c|c|c|c|}
\hline & $\begin{array}{l}\text { One stage } \\
\text { group }\end{array}$ & $\begin{array}{r}\text { Two st } \\
\text { grol }\end{array}$ & $\begin{array}{l}\text { tages } \\
\text { up }\end{array}$ & \multirow[t]{2}{*}{$t^{*}$} & \multirow{2}{*}{$p$-value } \\
\hline \multicolumn{4}{|c|}{ Mean SD Mean SD } & & \\
\hline $\mathrm{SSN} \rightarrow \mathrm{NAC}$ pr & re 20.931 .2 & 20.87 & 1.36 & 0.14 & $0.89 \mathrm{NS}$ \\
\hline $\mathrm{NAC} \rightarrow$ IML post & 7.30 & 7.87 & 0.72 & 1.96 & $0.06 \mathrm{NS}$ \\
\hline
\end{tabular}

Table (18): Comparison of post-operative complications between G1 and G2.

\begin{tabular}{|c|c|c|c|c|c|c|}
\hline & \multicolumn{2}{|c|}{ One stage group } & \multicolumn{2}{|c|}{ Two stages group } & \multirow{2}{*}{$\mathrm{X}^{2} *$} & \multirow{2}{*}{$p$-value } \\
\hline & $\mathrm{N}$ & $\%$ & $\mathrm{~N}$ & $\%$ & & \\
\hline \multicolumn{7}{|l|}{ Extrusion: } \\
\hline Yes & 0 & 0.0 & 0 & 0.0 & - & - \\
\hline No & 15 & 100.0 & 15 & 100.0 & & \\
\hline \multicolumn{7}{|l|}{ Infection: } \\
\hline Yes & 2 & 13.3 & 1 & 6.7 & 0.37 & 1.00 \\
\hline No & 13 & 86.7 & 14 & 93.3 & FE & NS \\
\hline \multicolumn{7}{|l|}{ Disruption: } \\
\hline Yes & 3 & 20.0 & 0 & 0.0 & 3.33 & 0.22 \\
\hline No & 12 & 80.0 & 15 & 100.0 & FE & NS \\
\hline \multicolumn{7}{|l|}{ Scar widening: } \\
\hline Yes & 5 & 33.3 & 7 & 46.7 & 0.56 & 0.46 \\
\hline No & 10 & 66.7 & 8 & 53.3 & & NS \\
\hline \multicolumn{7}{|l|}{ Capsular contracture: } \\
\hline Yes & 0 & 0.0 & 1 & 6.66 & 2.14 & 0.48 \\
\hline No & 15 & 100.0 & 14 & 93.33 & $\mathrm{FE}$ & NS \\
\hline Overall complications (per group) & 10 & 66.6 & 9 & 60 & & \\
\hline Overall complications (per all cases) & & & 19 & $3 \%)$ & & \\
\hline
\end{tabular}

*Chi square test.

Table (19): Comparison of BREAST-Q questionnaire pre-operative assessment between G1 and $\mathrm{G} 2$.

\begin{tabular}{|c|c|c|c|c|c|c|}
\hline & \multicolumn{4}{|c|}{ One stage group One stages group } & \multirow{2}{*}{$\begin{array}{l}\text { Value of test of } \\
\text { significance }\end{array}$} & \multirow{2}{*}{$\begin{array}{c}p- \\
\text { value }\end{array}$} \\
\hline & Mean & SD & Mean & SD & & \\
\hline Satisfaction with Breasts pre-op. & 19.47 & 20.95 & 15.60 & 17.34 & $0.44 *$ & $0.68 \mathrm{NS}$ \\
\hline Psychosocial Well-being pre-op. & 20.33 & 20.18 & 825.73 & 24.42 & $0.55 *$ & $0.60 \mathrm{NS}$ \\
\hline Physical Well-being pre-op. & 93.60 & 12.22 & 100.00 & O.OO & $2.03 * *$ & $0.06 \mathrm{NS}$ \\
\hline Sexual Well-being pre-op. & 19.33 & 16.47 & 724.27 & 19.73 & $0.74 * *$ & $0.46 \mathrm{NS}$ \\
\hline
\end{tabular}

* Mann-Whitney U test. **Student $t$-test.

Table (20): Comparison of BREAST-Q questionnaire post-operative assessment between G1 and G2.

\begin{tabular}{lccccccc}
\hline & \multicolumn{2}{c}{ One stage group } & \multicolumn{2}{c}{ One stages group } & & \multicolumn{1}{c}{$\begin{array}{c}p \text { - } \\
\text { value }\end{array}$} \\
\cline { 2 - 5 } & Mean & SD & Mean & SD & & & \\
\hline Satisfaction with Breasts post-op. & 74.93 & 16.33 & 71.87 & 18.72 & 0.48 & $0.64 \mathrm{NS}$ \\
satisfaction with outcome & 82.47 & 19.83 & 78.47 & 24.89 & 0.49 & $0.63 \mathrm{NS}$ \\
Psychosocial Well-being post-op. & 86.40 & 14.41 & 80.27 & 25.36 & 0.81 & $0.42 \mathrm{NS}$ \\
Sexual Well-being post-op. & 80.07 & 13.40 & 80.40 & 19.24 & 0.06 & $0.96 \mathrm{NS}$ \\
Physical Well-being post-op. & 93.53 & 11.03 & 89.13 & 14.45 & 0.94 & $0.36 \mathrm{NS}$ \\
Satisfaction with Information & 72.60 & 20.83 & 60.27 & 20.54 & 1.63 & $0.11 \mathrm{NS}$ \\
Satisfaction with Surgeon & 84.27 & 20.09 & 80.73 & 27.77 & 0.40 & $0.69 \mathrm{NS}$ \\
Satisfaction with Medical staff & 73.67 & 19.46 & 83.00 & 14.49 & 1.49 & $0.15 \mathrm{NS}$ \\
Satisfaction with Office Staff & 78.40 & 21.41 & 77.13 & 16.23 & 0.18 & $0.86 \mathrm{NS}$ \\
\hline
\end{tabular}

*Student $t$-test. 


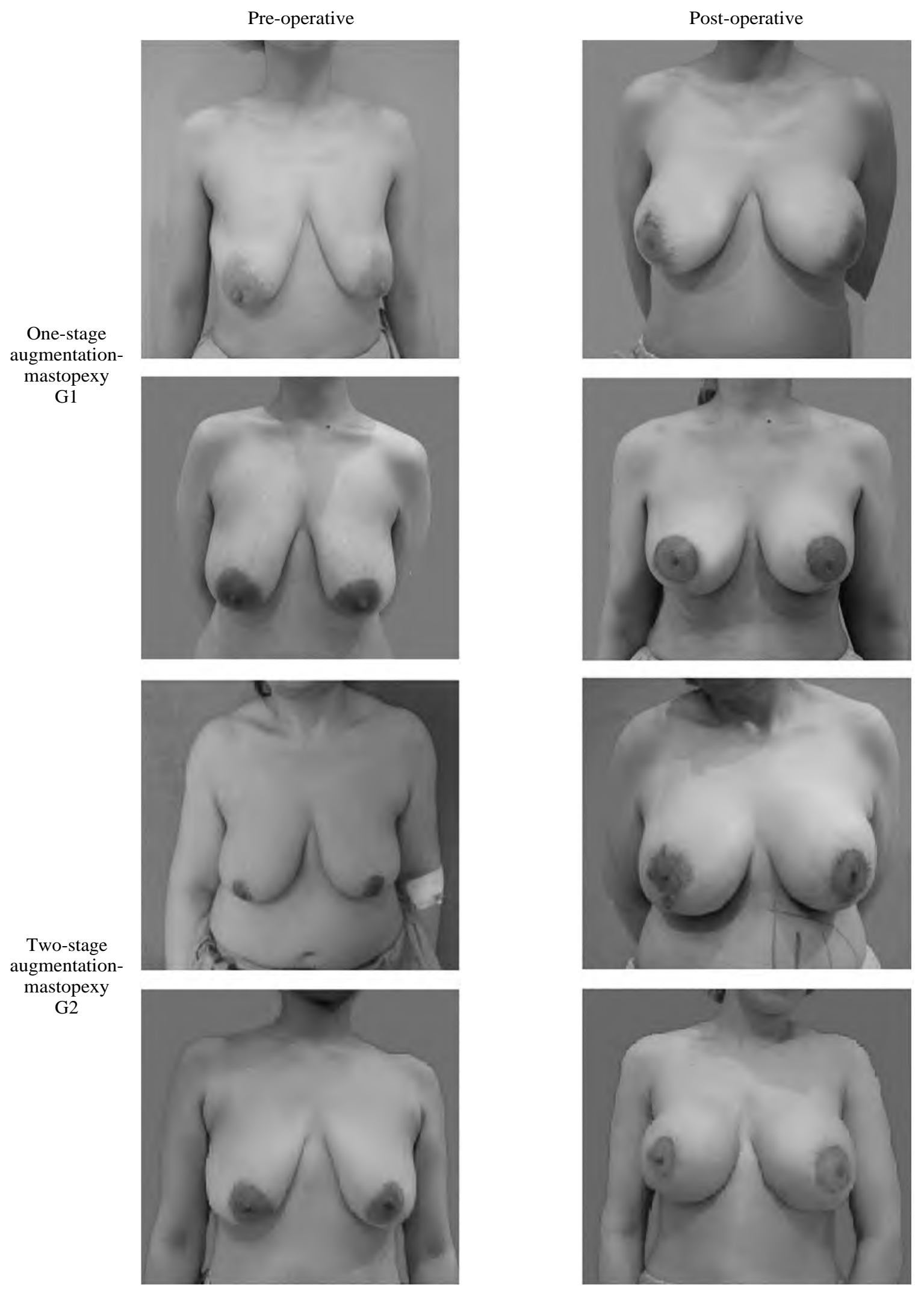

Fig. (4): Showing pre- and post-operative pictures of 2 cases of G1 (one-stage) and 2 cases of G2 (two-stage augmentation-mastopexy). 


\section{Discussion}

Augmentation-mastopexy, as being one of the most controversial operations in plastic surgery, many researches have discussed its outcome.

Recent literatures have raised the question of whether better results might be achieved by staging the procedure or doing it in one stage, some authors claimed that the safest strategy in breast ptosis patients with grade III is a 2-stage approach separating the mastopexy and the augmentation into 2 separate procedures [7].

From the patients' side, although it seems intuitive that a combined procedure may carry less predictable results than each procedure alone, it is obvious that most patients still prefer a one-stage operation because they are often uncomfortable about the thought of a second operation so most patients prefer a final result from a single operation [10].

Some studies claims that one-stage augmentation mastopexy can be safely performed with a reoperation rate that is significantly lower than when the procedure is staged, as satisfying results can be achieved safely and effectively with the appropriate patient selection and operative techniques [12].

Moreover, some authors reported that augmentation-mastopexy provides complication and revision rates that are lower than the calculated cumulative rates for the procedures performed separately [13].

However, simultaneous augmentationmastopexy has been reported to be one of the most complex breast procedures, its difficulty is due to the fact that it is obligatory to manipulate all variables that determines the final shape of the breast by this combined procedure to some degree [9].

Therefore, some authors consider that combination of breast augmentation and mastopexy in one stage extremely increases the risk of complications than either surgery carried alone [14].

For example, loss of the nipple, although it is not a complication typically associated with either mastopexy or augmentation alone, it is a risk of augmentation-mastopexy when the two operations are combined [14].

In 2014, Spear et al., discussed the more complex nature of both the patient's problems and the surgical procedure itself in augmentationmastopexy. The Spear and Swanson prospective outcomes studies evaluated and compared mastopexy and augmentation-mastopexy from the patient perspective, however, the Swanson study was biased by very short follow-up and lack of anonymity [15].

Many ways to assess aesthetic outcome after breast surgery have been used in literatures, these include both objective clinician rating of the outcome through photo scoring, and recently quantitative analysis of breast volume, contour, projection and symmetry through use of complicated threedimensional photography and photo-scoring software [15].

Although the objective data provides important information to researchers and clinicians, but they are not sufficient to complete the outcome discussion because they fail to take into account the patient viewpoint which may differ significantly from that of the clinician evaluator [11].

Pusic et al., have developed an outcome measure for breast surgery, the BREAST-Q questionnaire which provides three general indices, breast satisfaction, psychosocial wellbeing and sexual wellbeing, although it provides a good indication for post-operative patient satisfaction and quality of life, it can't provide data regarding the clinical progression of cases and complications [11].

In our study work, we conducted a literature search on patient reported data together with clinical assessment. To our knowledge, little published studies comparatively describe the quality of life described by patients along with the clinical complications and outcome observed by surgeons regarding the two surgical techniques of augmentation-mastopexy.

Regarding demographic data, In this study the mean age group was $32.80 \pm 8.55$ in one stage group AND 36.07 \pm 7.23 in the two stages group; with no significant difference in age between the two groups and no relationship between age and degree of ptosis also the average of patient with ${ }^{2 n d}$ degree ptosis in one stage group was $100 \%$ vs. $86.7 \%$ in two stages group and $13.3 \%$ had ${ }^{\text {3rd }}$ degree ptosis. Our mean follow-up time was 2.5 years.

Regarding the incision and the final scar shape of our study cases, in G1: 8 cases did a peri-areolar mastopexy (53.3\%) and 7 cases did a vertical mastopexy (46.7\%), all cases of two stages group did a vertical mastopexy. 
Regarding the implant, in our study, we used silicone implant of size between $275 \mathrm{ml}$ and $315 \mathrm{ml}$. All cases were subjected to a sub-glandular implant.

In this work, change in the measurements post operatively was significant for all cases in our study but there was no significant difference between the two study groups, breast ptosis was corrected in all the 30 cases and no recurrent ptosis till the last follow-up date.

Regarding patient satisfaction, the two groups $\mathrm{G} 1$ and $\mathrm{G} 2$ reached satisfaction about the breast after operation by $75 \%$ and $72 \%$ respectively with increase in satisfaction than before surgery by $55.47 \%$ and $56.27 \%$. G1 was satisfied with outcome of operation by $82.47 \%$ vs. $78.47 \%$ in G2. Psychosocial wellbeing increased by $66.07 \%$ in G1 vs. $54.54 \%$ in G2. Physical wellbeing regarding breast area showed $0.07 \%$ decrease in G1 vs. decrease by $10.87 \%$ in G2 in form of pain and discomfort in chest and breast during exercise. Sexual wellbeing and confidence in breast area and in front of partner were increased by $60.74 \%$ in G1 vs. $56.14 \%$ in $\mathrm{G} 2$.

Regarding complications, in our study, most complication observed in both study groups was scar widening by average of $(33.3 \%)$ in one stage group and $(46.7 \%)$ in two stages group. Wound disruption was noticed in one stage group only by average of $(20.0 \%)$. Capsular contracture was noticed in two stages group only by average of $(6.66 \%)$ and was of grade II. No extrusion of implant in both groups of our study. The overall percentage of complication of our study cases (including scar widening as a complication) is $(63.3 \%)$ for the whole population and for each group is $(66.7 \%)$ and $(60 \%)$ in raw.

Regarding the correction of breast ptosis, our results showed that there is no significant difference between doing the augmentation-mastopexy using silicone implant in single stage, and staging the procedure; a mastopexy operation followed by breast augmentation in a second stage.

Swanson in 2013, [13] compared a 784 cases performing breast augmentation and vertical mammoplasty both individually and in combination. In his prospective study, the mean age was $36.5 \pm 10.7$ ranging from 16.8-80.9 and his average follow-up time was 8.6 months. In our study G1 and G2 mean age was $32.80 \pm 8.55$ and $36.07 \pm 7.23$ respectively with a range between 20 and 49, and our average follow-up time was 2.5 years. In Swanson [13] study, he placed the implant sub-muscularly, which had a wide volume range (125-925ml). While in our study the implants were placed in the subglandular plane which had narrow range of volumes (275-315ml). Swanson [13] noted that the incidence of complications was $(25.0 \%)$ overall, and was significantly lower for breast augmentation (17.6\%) than for vertical mastopexy (33.3\%) and augmentation-mastopexy (36.3\%). Based on the individual procedural risks, a cumulative complication rate of $(45.0 \%)$ was calculated for a theoretical patient treated with mastopexy followed by implants. The overall percentage of complication of our study cases (including scar widening as a complication) is $(63.3 \%)$ for the whole population and for each group is $(66.7 \%)$ and $(60 \%)$ in raw. Swanson's [13] study concluded that vertical mammo-plasty may be used to correct ptosis in breasts of all sizes. Vertical augmentation-mastopexy provides complications and revision rates that are less than the calculated cumulative rates for the procedures performed separately. The combined procedure offers technical advantages and permits safe singlestage surgery using the vertical technique.

In 2014, Castello [16] retrospectively reviewed his experience operating on 107 patients who underwent simultaneous augmentation mastopexy over a 5-years period for an average of 14.7 months. The average age was 42 years, ranges from 26 to 69 years. In our study we retrospectively and prospectively observed the patients over a 4 -years period and our average follow-up time was 2.5 years. G1 and G2 mean age was $32.80 \pm 8.55$ and $36.07 \pm 7.23$ respectively with a range between 20 and 49 years of age. Castello [16] used breast implants with mean volume of $240 \pm 30 \mathrm{ml}$; he used the sub-glandular plane for the implant in 70 patients, and sub-pectoral placement in the remaining 37 cases. In our study the implants were placed also in the sub-glandular plane with mean volume of $295 \pm 20 \mathrm{ml}$. In Castello [16] study, a peri-areolar mastopexy scar was used in $11 \%$ of cases, $47 \%$ had a vertical approach and in $31 \%$ patients an inverted-T scar mastopexy was used. In our study, in G1 53\% of patients had a peri-areolar and $47 \%$ had a vertical one-stage augmentation-mastopexy, in G2 all patients had a vertical scar mastopexy followed by augmentation in the seconed stage. In Castillo [16] study, the results of a questionnaire of patient's self- assessment from 0 to 6 scale mean score was as the following: Size of breast 4.23 $( \pm 0.3)$, Shape of breast $4.38( \pm 0.6)$, Breast symmetry $4.06( \pm 0.4)$, NAC location $3.96( \pm 0.7)$, Overall aesthetic outcome $4.31( \pm 0.38)$. A 6-grade scale was used in each category: $5=$ Very satisfied, $4=$ Good, $3=$ Acceptable, $2=$ Bad, $1=$ Very bad and $0=$ Failed. In our study we used a different scale of evaluation by applying the standard satisfaction 
BREAST-Q questionnaire which uses a percentage values. According to Castillo, [16] a very low overall complication rate of $14 \%$ was observed and a reoperation rate of $12.1 \%$ at 14.7 months and two patients from the total 107 cases developed capsular contracture. The overall percentage of complication of our study cases (including scar widening as a complication) is $63.3 \%$ for the whole population and for each group is $66.7 \%$ and $60 \%$ in raw including one case of $\mathrm{G} 2$ from the 30 patients of the study had a capsular contracture. Castillo [16] concluded that simultaneous augmentationmastopexy is an effective and versatile way to lift the NAC, tighten the breast skin, increase breast projection, and filling the upper pole and through a peri-areolar approach, an excellent correction of pre-existing ptosis is achieved, also patient satisfaction with the results of this procedure was extremely high.

Also in 2014, Stevens [10] observed 615 cases of breast augmentation and mastopexy. In his retrospective chart review on 186 consecutive patients underwent one-stage augmentationmastopexy, the average age of patients was 39 years, range from 17 to 78 years. In our study we retrospectively and prospectively observed the patients. $\mathrm{G} 1$ and $\mathrm{G} 2$ average age was 33 and 36 respectively with a range between 20 and 49 years of age. The mean implant volume by Stevens [10] was $320 \mathrm{ml}$, with $7 \%$ of cases had a sub-glandular implant and the rest had sub-muscular, $44 \%$ of patients received saline implants and $56 \%$ had silicone implants. In our study, all the implants were silicone and all placed in the sub-glandular plane with mean volume of $295 \mathrm{ml}$. In Stevens study, Inverted-T mastopexy was performed in $60 \%$ of cases, circum-areolar in $24 \%$ of cases, and vertical for most of the remainder. In our study, in G1 $53 \%$ of patients had a peri-areolar and $47 \%$ had a vertical one-stage augmentation-mastopexy, in $\mathrm{G} 2$ all patients had a vertical scar mastopexy followed by augmentation in the second stage. Stevens [10] listed that only 1 patient developed a late infection and needed removal of the implant, the most common complication was saline implant deflation by $5.9 \%$. A $16.7 \%$ of patients underwent revision surgery within the average 42 -month follow-up period. In our study, the most common complication was scar widening by $33.3 \%$ in G1 and $46.7 \%$ in $\mathrm{G} 2$ and no cases required revision. Stevens [10] concluded that; although one-stage augmentation-mastopexy operation is not without risks and despite the average chance of requiring revision for a one-stage procedure, this still significantly lower than the $100 \%$ necessity for a second operation inherent in two-stage procedures, each of which still may require revision.

Khan in 2016, [17] studied a total of 1,406 patients retrospectively 1,298 had augmentation mammoplasty as (Group A) and 108 patients had simultaneous augmentation mastopexy as (Group B). The mean age of the patients in Group A and B was $29.6 \pm 8.62$ years (range: $18-67$ years) and $32.2 \pm 9.50$ years (range: $18-67$ years), respectively. Mean follow-up was 4.5 years (range: 3 months to 10 years). In our study, we compared 15 patients having augmentation-mastopexy in one session as group 1 and 15 patients having the procedure in two stages as group 2, the mean age for G1 and G2 was $32.80 \pm 8.55$ and $36.07 \pm 7.23$ respectively with a range between 20 and 49, and our average follow-up time was 2.5 years. Khan [17] used round cohesive gel textured silicone implants by mean size of the implants in Group A and B of $340 \mathrm{~mL}$ and $308 \mathrm{ml}$ respectively, placed in muscle splitting biplane. In our study, same implant type was used with mean volume of $295 \pm 20 \mathrm{ml}$ in G1 and G2, but was placed in the sub-glandular plane. Khan [17] found that wound infection in Group A and B was seen in $(0.6 \%)$ and $(3.7 \%)$ and wound breakdown was seen in $(1.1 \%)$ in Group A as compared to $(6.5 \%)$ in Group B. in our study, wound infection in $\mathrm{G} 1$ and $\mathrm{G} 2$ was $13.3 \%$ and $6.7 \%$, and wound breakdown was $20 \%$ and $0.0 \%$ respectively. In Khan's study, [17] a total of 5 patients were treated for Grade IV capsular contracture, of these patients, $4(0.32 \%)$ belonged to the augmentation mammoplasty (Group A) and $1(0.9 \%)$ from augmentation mastopexy (Group B). In our study, one patient (6.6\%) of GII developed capsular contracture of Grade II versus no patients of G1. Khan [17] concluded that there was a statistically and clinically significant higher rate of complications and revision rate noted in simultaneous augmentation with mastopexy (Group B) as compared to augmentation mammoplasty alone (Group A). However, the rise in complications rate is sum of the complications of the two individual components performed and not exponential.

In 2018, Kalaaji [15] published a comparative anonymous study between 61 patients having breast augmentation with implants (BI) and 37 patients, who underwent augmentation-mastopexy (AM) between 2005 and 2009 at the Oslo Plastic Surgery Clinic, who were given a 47-question survey to measure quality of life, the mean follow-up time was 2.8 years in both groups. In our study we used a different scale of evaluation by applying the standard satisfaction BREAST-Q questionnaire which uses a percentage values. In Kalaaji [15] 
study, the effects on psychosocial aspects were significant in the BI group regarding life changes and feeling like a "whole" person $(68.9 \%$ vs. $40.5 \%$ and $73.8 \%$ vs. $40 \%$ ). BI group also had a significantly higher satisfaction with overall cosmetic result, enlargement, and breast volume (93.4\%, $90.2 \%, 80 \%$ vs. $69.4 \%, 70.2 \%$ vs. $67 \%$ in AM group). Additionally, the BI group was more satisfied with shape, scar, and symmetry $(90.1 \%$ vs. $63.9 \%, 70.6 \%$ vs. $40.5 \%$, and $83.6 \%$ vs. $54.0 \%$, respectively). In our study, the two groups G1 and G2 reached satisfaction about the breast after operation by $75 \%$ and $72 \%$ respectively with increase in satisfaction than before surgery by $55.47 \%$ and $56.27 \%$, G1 was satisfied with outcome of operation by $82.47 \%$ vs. $78.47 \%$ in G2, psychosocial wellbeing increased by $66.07 \%$ in G1 vs. $54.54 \%$ in G2. Kalaaji [15] discussed the most common complications among both groups from the patient's point of view. BI patients reported a higher rate in "no complications" post-operative (78.1\%) than AM patients (62.2\%). BI had "Bleeding that leads to re-operation" in $1.7 \%$ vs. $0 \%$ and "Rippling" in $15.3 \%$ vs. $10.8 \%$, respectively. Concerning the capsular contracture that did lead to correction, it was noted as low incidence in both groups (1.7\% vs. $5.4 \%$, respectively). While BI patients had no post-operative problems with seroma formation, $2.7 \%$ in the AM group experienced this complication. Only two patients of each group (3.2\% and 5.4\%, respectively) got an infection which needed to be treated. In our study, we monitored the complications clinically. $13.3 \%$ of cases in G1 had wound infection vs. $6.67 \%$ in G2, $20 \%$ of cases in G1 had wound disruption vs. no disruption noticed in G2, scar widening reached up to $46.67 \%$ of cases in G2 (after 2nd stage) vs. $33.3 \%$ in $\mathrm{G} 1$, also capsular contracture happened in one case only of $\mathrm{G} 2$ by incidence of $6.66 \%$ vs. no incidence in cases of G1, no extrusion of implant in both groups. Khalaji [15] concluded that satisfaction with overall cosmetic results and with overall enlargement was significantly higher in breast implant patients than augmentationmastopexy patients, and this could be attributed to the already good skin quality of the patient being elected for only augmentation. The less favorable results with AM show the importance of providing better information to the patients, improving the surgical techniques, and following-up with patients.

In general, all studies meet at the point that augmentation-mastopexy if done in one session with the careful patient selection and proper techniques intra operatively, results will reach that of the two stages but in a single operation with no added risks, hence, more acceptance among patients and less morbidity will be achieved.

\section{Conclusion:}

A more obvious comparative values between the two techniques and late post-operative complications and long-term results need to be determined by further studies on a larger scale of patients and longer duration of follow-up.

\section{References}

1- BROWN D.L., BORSCHEL G.H. and LEVI B.: Michigan manual of plastic surgery. Lippincott Williams \& Wilkins, Apr. 9, 2014.

2- RUBIN J.P. and KHACHI G.: Mastopexy after massive weight loss: Dermal suspension and selective autoaugmentation. Clinics in Plastic Surgery, 1; 35 (1): 1239, 2008.

3- RINKER B., VENERACION M. and WALSH C.P.: Breast ptosis: Causes and cure. Annals of Plastic Surgery, 64 (5): 579-84, 2010.

4- AREFANIAN S., AZIZADDINI S., NEISHABOURY M., ZAND S., SAADAT S. and KAVIANI A.: A Study on Predisposing Factors to Breast Ptosis. Archives of Breast Cancer, 63-7, 2018.

5- HURWITZ D.J. and AGHA-MOHAMMADI S.: Postbariatric surgery breast reshaping: The spiral flap. Annals of Plastic Surgery, 56 (5): 481-6, 2006.

6- FERRARO G.A., De FRANCESCO F., RAZZANO S., D'ANDREA F. and NICOLETTI G.: Augmentation mastopexy with implant and autologous tissue for correction of moderate/severe ptosis. Journal of Investigative Surgery, 29 (1): 40-50, 2016.

7- COLWELL A.S., DRISCOLL D. and BREUING K.H.: Mastopexy techniques after massive weight loss: An algorithmic approach and review of the literature. Annals of Plastic Surgery, 63 (1): 28-33, 2009.

8- LEE M.R., UNGER J.G. and ADAMS W.P.: The tissuebased triad: A process approach to augmentation mastopexy. Plastic and Reconstructive Surgery, 134 (2): 215$25,2014$.

9- KARACAOGLU E.: Single stage augmentation mastopexy: A novel technique using autologous dermal graft. Annals of Plastic Surgery, 63 (6): 600-4, 2009.

10- STEVENS W.G., STOKER D.A., FREEMAN M.E., QUARDT S.M., HIRSCH E.M. and COHEN R.: Is onestage breast augmentation with mastopexy safe and effective? A review of 186 primary cases. Aesthetic Surgery Journal, 26 (6): 674-81, 2006.

11- PUSIC A.L., REAVEY P.L., KLASSEN A.F., SCOTT A., McCARTHY C. and CANO S.J.: Measuring patient outcomes in breast augmentation: Introducing the BREASTQ๑ augmentation module. Clinics in Plastic Surgery, 36 (1): 23-32, 2009.

12- MESSA C.A.: Primary One-Stage Augmentation Mastopexy: A 10-Year Retrospective Review of 725 Consecutive Cases. Journal of the American College of Surgeons, 225 (4): e41, 2017. 
13- SWANSON E.: Prospective comparative clinical evaluation of 784 consecutive cases of breast augmentation and vertical mammaplasty, performed individually and in combination. Plastic and Reconstructive Surgery, 132 (1): 30-45, 2013.

14- SPEAR S.L., DAYAN J.H. and CLEMENS M.W.: Augmentation mastopexy. Clinics in Plastic Surgery, 36 (1): 105-15, 2009.

15- KALAAJI A., DREYER S., BRINKMANN J., MARIC I., NORDAHL C. and OLAFSEN K.: Quality of life after breast enlargement with implants versus augmentation mastopexy: A comparative study. Aesthetic Surgery Journal, 38 (12): 1304-15, 2018.

16- CASTELLO M.F., SILVESTRI A., NICOLI F., DASHTI T., HAN S., GRASSETTI L., TORRESETTI M., PERDANASARI A.T., ZHANG Y.X., Di BENEDETTO G. and LAZZERI D.: Augmentation mammoplasty / mastopexy: Lessons learned from 107 aesthetic cases. Aesthetic Plastic Surgery, 38 (5): 896-907, 2014.

17- KHAN U.D.: Augmentation mastopexy and augmentation mammoplasty: An analysis of 1,406 consecutive cases. Plast. Aesthet. Research, 3: 26-30.

\section{دراسة مقارثة بين أجزاء عملية رفع الثدى ومرئ فى مرحلة واحدة ومرحلتين عملين}

الخلفية: ترهل الثدى هو مشكلة اجتماعية متزايدة تسبب تثوها جسدياً وتفسياً والتى حظيت بأ هتهام أكبر فى الآونة الأخيرة. يتم تصحيع

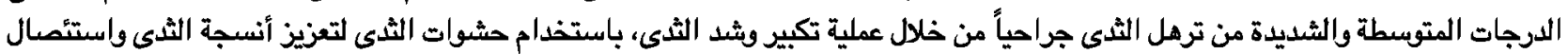

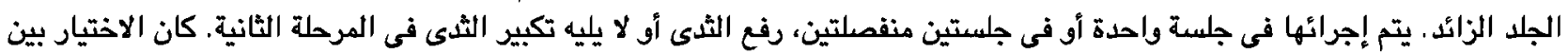

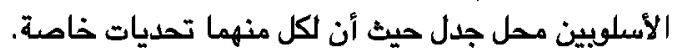

الهدف: إجراء مقارنة بين الطريقتين فى علاج الدرجة الثانية والثالثة من ترهل الثدى، رفع وتكبير الثدى باستخدام حشوات السيليكن

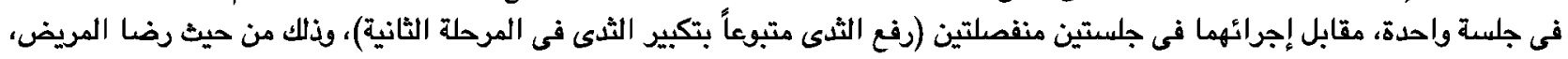

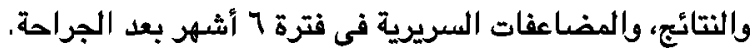

المرضى وطرق الهلاج: هذه دراسة جماعية بائر رجعى تقارن بين تقنيتى رفع وتكبير الثدى فيما يتعلق برضا المريض وجودة الصياة وأيضاً

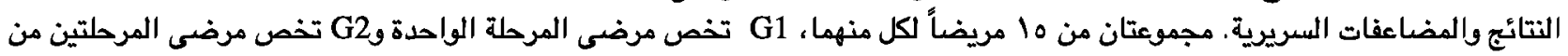

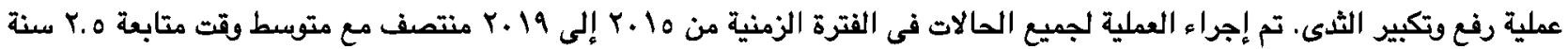

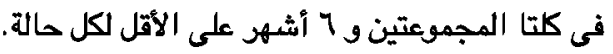

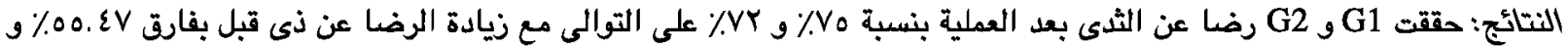

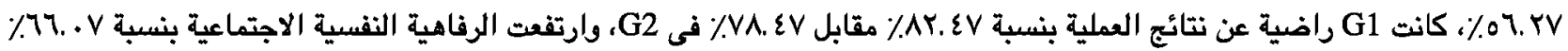

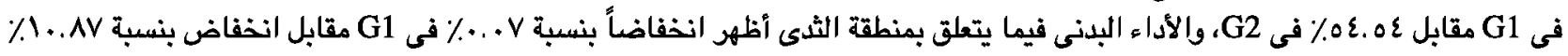

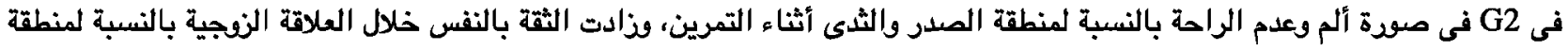

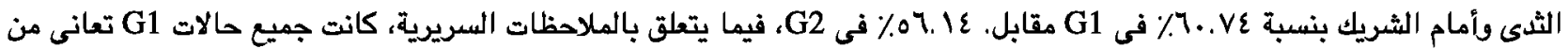

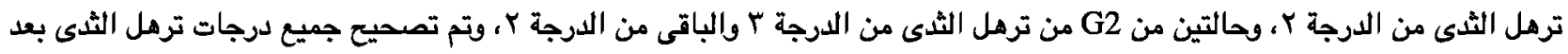

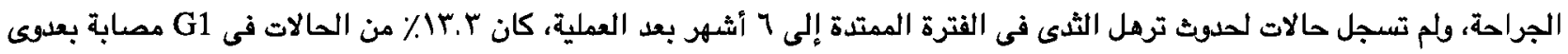

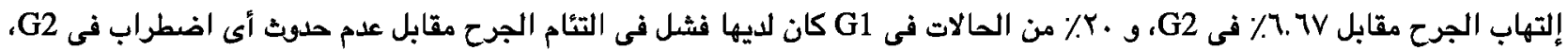

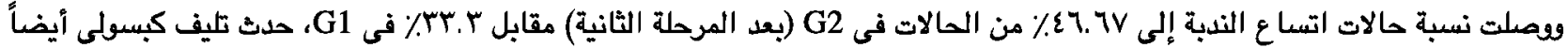

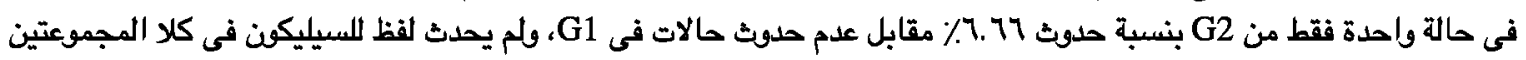

الخلاصة: كثفت الدراسة أن كلتا الطريقتين فعالتان في علاج ترهل الثدى مع عدم وجود اختلاف كبير فى رضا المرضى والمضاعفات

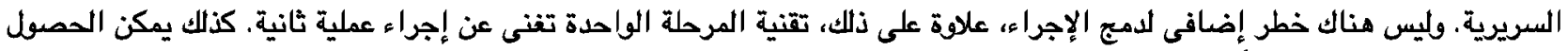

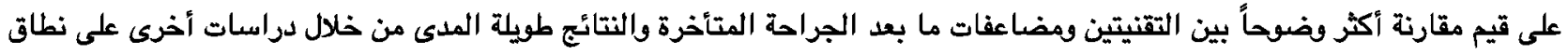
أكبر من المرضى قلمعدة متابعة أطول. 